\title{
STATISTICAL OPTIMIZATION OF LACTIC ACID EXTRACTION USING GREEN SOLVENT AND MIXED EXTRACTANTS (TOA AND TOMAC)
}

\author{
Anil Kumar ${ }^{1}$ and Avinash Thakur ${ }^{2 *}$ \\ ${ }^{1,2}$ Research Laboratory-III, Department of Chemical Engineering, Sant Longowal Institute of Engineering and \\ Technology, Longowal - 148 106, Punjab, India
}

Received: 10 October 2017; received in revised form 14 November 2019

\begin{abstract}
Since some previous years, reactive extraction has become more attractive and competitive technique for the separation and purification of lower carboxylic acids from fermentation broth as well as from dilute aqueous streams. This paper shows the results of investigation of reactive extraction of lactic acid (LA) from an aqueous solution using the synergistic mixture of the extractants (TOA (tri-n-octylamine) and TOMAC (Tri-n-octylmethylammonium chloride)) and a non-toxic and biocompatible green solvent (soybean oil). Three-level Box-Behnken design (BBD) under response surface methodology (RSM) was opted for the experimental design and to interpret the mutual effect of seven independent process parameters on the LA distribution coefficient $\left(K_{\mathrm{D}}\right)$. The maximum values of LA distribution coefficient $\left(K_{\mathrm{D}}=2.51\right)$ and its extraction efficiency $(\eta=71.5 \%)$ were obtained for the optimum values of various process parameters such as $0.02[\mathrm{M}]$ initial LA concentration $\left(C_{1}\right), 0.5(\mathrm{v} / \mathrm{v})$ extractant ratio $(\alpha), 28.66 \%(\mathrm{v} / \mathrm{v})$ mixed extractants concentration $(\Psi), 2(\mathrm{v} / \mathrm{v})$ phase ratio $(\Phi), 27{ }^{\circ} \mathrm{C}$ temperature $(T), 102 \mathrm{rpm}$ stirring speed $(\omega)$, and 63 min contact time $(\tau)$. This present investigation will provide a noble discussion on LA reactive extraction using green solvent and on various influencing process parameters for gaining the enhanced value of LA distribution coefficient $\left(K_{\mathrm{D}}\right)$.
\end{abstract}

Key Words: Reactive extraction, Tri-n-octylamine, Soybean oil, Lactic acid, Response surface methodology

DOI: https://doi.org/10.3329/cerb.v21i1.47369

\section{Introduction}

Lactic acid (LA) has very wide scope of its application in various industrial sectors such as in polymer sector (for making biodegradable plastic bags and re-absorbable plates), food sector (as an acidulant and buffering agent), chemical sector (as descaling agent, $\mathrm{pH}$ regulator, neutralizer, and cleaning agent), and more recently in medical sector (to make screws, plates, and pins) [1, 2]. LA (2-hydroxypropanoic acid) is a lower carboxylic acid with chemical formula $\left[\mathrm{C}_{3} \mathrm{H}_{6} \mathrm{O}_{3}\right]$. LA gives the lactate ion $\left[\mathrm{CH}_{3} \mathrm{CH}(\mathrm{OH}) \mathrm{COO}^{-}\right]$by losing a proton from the acidic group and it is soluble in water and water-miscible organic solvents but not in the organic solvents $[1,3]$. LA participates in many industrial chemical reactions such as esterification, condensation, and polymerization [4]. LA is a largely available organic acid in nature [5]. It was discovered by famous Swedish scientist Carl Wilhelm Scheele in 1780. The first large- scale production of LA in the United States of America was the result of the discovery of a French Scientist Fremy who obtained LA by the fermentation process $[1,6]$.

The conventional method of LA recovery is not so competitive and also environmentally un-friendly since it gives only the salt of LA instead of pure LA because of the addition of alkalis (like $\mathrm{NaOH}$ and $\left.\mathrm{Ca}(\mathrm{OH})_{2}\right)$ which are needed for $\mathrm{pH}$ adjustment. It increases the production cost of LA up to $50 \%$ because of the addition of chemicals as well as some additional separation and purification steps [7]. It mainly depends on the concentration of clarified fermentation liquor and re-acidification with sulphuric acid $\left(\mathrm{H}_{2} \mathrm{SO}_{4}\right)$ to give crude LA [8]. Therefore, high cost and environmental pollution posed by the conventional method had led to search other methods for the recovery of LA. The successfully developed methods of LA recovery are as follows solvent extraction, membrane bioreactor, liquid surfactant membrane extraction, 
adsorption and electro dialysis. Each method possesses some own merits and demerits but among all, reactive extraction specifically has added some advantages (such as a clean process due to the complete recovery of the diluents, highly selective, economic, gives high product yield, easy product removal [9], good control on broth $\mathrm{pH}$ without use of any base, has high value of both local mass transfer and distribution coefficient, decreasing in equipment size, utility costs, by-product reactions, and better recovery of product with high purity [10]) over the other methods [1, 11]. In the process of reactive extraction, first the reaction takes place between the extractant molecule which presents in the organic phase and the solute (LA) molecule in the aqueous phase and then formed a complex (acidextractant) which solubilizes in the organic phase [12]. The studies of binary diluents and extractants for the LA extraction from the aqueous solution as well as from the fermentation broth have been become the current topic of research in view of their improved stripping behavior. For example Poposkaet al.[13] had reported about the reactive extraction of tartaric acid using Hostarex A324 in isodecyl alcohol/kerosene mixtures, Uslu and Inci,[14] have studied the extraction of propionic acid using Aliquat336, five single solvents, and three binary solvents, and Moraleset al. [15] had examined the effect of various extractants (tri-ntributyl phosphate (TBP) and tri-n-octylamine (TOA) in 1-decanol/n-dodecane) on the extraction of monocarboxylic acids. Supercritical fluid $\left(\mathrm{CO}_{2}\right)$ extraction is another method for the recovery and purification of LA but it involves limitations such as low purity of product due to the co-extraction of fermentation by-products such as acetic and butyric acids and also involvement of huge capital [16].

At present, reactive extraction has become a very promising technique for the recovery of LA from the fermentation broth as well as from the dilute waste streams since this method gives high purity product with the reduced cost and minimum environment pollution but it suffers from the problems of toxicity of the used extractants/carriers and organic diluents [17]. The petroleum-based organic diluents are usually toxic, non-renewable, non-biodegradable, flammable, volatile in nature, and harmful for the aquatic life in case of solvent loss due to entrainment in the aqueous phase. Therefore, there is paramount need to find-out a greener replacement of the petroleumbased organic solvents in order to curb the environment related problems [18]. The problems of toxicity during the reactive extraction of LA can be minimized either by choosing non-toxic diluent i.e. vegetable oils (such as soybean oil, rice bran oil, sunflower oil etc.) for blending with a toxic extractant to yield a biocompatible mixture or a combination of a non-toxic extractant (such as TOA which is non-toxic to anaerobic bacteria [19]) and a diluents [20]. Vegetable oils or green solvents have a great potential as a greener substitute for the organic solvents because of their sound pertinent properties like non-toxicity, non flammability, non-volatility, renewability, and biodegradability [18]. To the best of our knowledge till date no work has been reported in the literature for the use of soybean oil as a green solvent for LA extraction from the aqueous solution. Soybean oil (kinematic viscosity at $38{ }^{\circ} \mathrm{C}$ of $32.6 \mathrm{~mm}^{2} / \mathrm{s}$, refractive index at $20^{\circ} \mathrm{C}$ of 1.47 , and density of $0.9138 \mathrm{~kg} / 1$ [21]) is non-volatile oil extracted from soybean seeds, and contains, mainly linoleic acid $(47.2 \%)$, oleic acid $(25 \%)$, saturated acid (19.2\%), and linolenic acid (8.46\%), in the form of triglyceride [22].

For the optimization of various process parameters, the previous method of optimization is not useful since this method of single factor optimization by keeping all other parameters at a fixed value does not elucidate the interactive effect of all the involved process parameters [23]. Response surface methodology (RSM) is a very important statistical tool available as software for the optimization of various process variables, and for guessing the best performance conditions with the minimum number of experiments. It is a combination of statistical and mathematical methods which are helpful in the development, improvement, and optimization of the processes [24]. The LA distribution coefficient $\left(K_{\mathrm{D}}\right)$ was optimised by using the method of reactive extraction and its experiment run based on the 
experimental design received from Box-Behnken design (BBD) with seven variables at 3-levels each using Design Expert 7.16 software (Stat ease Inc., Minneapolis, USA). The main purpose of this present investigation is to study the major process variables (initial LA concentration in aqueous phase $\left(C_{1},[\mathrm{M})\right.$, extractant ratio $(\alpha, \mathrm{v} / \mathrm{v})$, mixed extractants concentration $(\Psi, \%(\mathrm{v} / \mathrm{v}))$, phase ratio $(\Phi, \mathrm{v} / \mathrm{v})$, temperature $\left(T,{ }^{\circ} \mathrm{C}\right)$, stirring speed $(\omega$, rpm), and contact time ( $\tau, \min )$ ) influencing the LA distribution coefficient $\left(K_{\mathrm{D}}\right)$, to optimize the process conditions, and also to find out a suitable and selective combination of non-toxic extractants and green diluent for the LA reactive extraction from the aqueous solution.

\section{Materials and Methods}

\subsection{Reagents}

All the reagents were of technical grade and used without any pre-treatment. Tri-n-octylamine (TOA), a tertiary amine, a light colourless liquid with the molar mass 353.66 and density $0.809 \frac{\mathrm{g}}{\mathrm{cm}^{3}}$ was procured from MERCK, Ltd, India. Tri-noctylmethylammonium chloride (TOMAC), a quaternary amine, with molar mass 404.17 and density $0.888 \mathrm{~g} / \mathrm{cm}^{3}$ was supplied by S.D. FineChem. Ltd, India. Lactic acid (LA) and sodium hydroxide pellets were purchased from S.D. FineChem. Ltd, India. Phenolphthalein solution $(\mathrm{pH}$ range, 8.2 to 10) used as an indicator was bought from $\mathrm{CDH}$, Ltd, India. Refined soybean oil as a green solvent was procured from the local market.

\subsection{Liquid - Liquid Extraction}

The organic phase in this study was composed of extractants/carriers (such as TOA and TOMAC), organic solvent, and green solvent (soybean oil). The aqueous phase with the desired LA concentration was prepared using LA and Milli-Q deionized water (Millipore filtration of MERCK). Both the phases in the desired phase ratio (0.5 - 2, $\mathrm{v} / \mathrm{v})$ were mixed into each-other and the resultant solution was shaken for different time intervals in a temperature-controlled incubator (New BrunswickTM Innova ${ }^{\circledR} 40$ ) for the rpm in the range of 50 - 200. After mixing of both the phases, these were left for half an hour for exact phase separation. Two phases were formed after settling down of the solution, one phase was settled at the top as an organic phase and other at the bottom as an aqueous phase. Samples were taken from the aqueous layer using a pipette/syringe for titration. The concentration of aqueous phase was determined by using acid-base titration and reconfirmed by the method of colorimetric by using UV/VIS - spectrophotometer (model DR $5000 \mathrm{HACH}$, USA) and absorbance recorded at $570 \mathrm{~nm}$ [25]. The organic phase concentration was determined by the mass balance.

\section{Theory of LA Extraction}

The overall extraction equilibrium of LA can be described by un-facilitated as well as the facilitated transport as:

\subsection{Physical Extraction}

The physical extraction of LA has studied for the better understanding of the effect of various extractants (TOMAC and TOA) on the reactive extraction of the LA [26]. In the aqueous phase LA (weak carboxylic acid) molecule exists as a monomer since hydrogen bonding of LA molecule along with the water molecule is much stronger than intermolecular hydrogen bonding between acid. But in the organic solution, maximum part of LA exists as dimers in the low polar or non-polar diluents [27]. LA exists in dissociated form $\left(A^{-}\right)$in the aqueous phase when the aqueous solution $\mathrm{pH}$ is less than its acid dissociation constant $\left(p K_{a}=\right.$ 3.86). If the $\mathrm{pH}$ value of the aqueous solution is less than its dissociation constant then the acid is assumed to be transferred from aqueous phase to organic phase by the three different steps: (i) ionization of acid in the aqueous phase (ii) undissociated acid partition in organic phase and, (iii) dimerization of acid in organic phase [28] as discussed below.

Ionization or dissociation of the LA in the aqueous phase:

$\underbrace{[\mathrm{HA}]}_{\mathrm{LA}} \leftrightarrow \underbrace{H^{+}}_{\text {Hydronium }}+\underbrace{A^{-}}_{\text {Lactate ion }}$ 
Partition of the un-dissociated acid molecule:

$[H A]_{\text {aq. }} \leftrightarrow[H A]_{\text {org }}$

Dimerization of the acid in the organic solvent:

$[(H A) 2]_{\text {org } .} \leftrightarrow[H A]_{\text {org }}^{2}$

\subsection{Lactic Acid Reactive Extraction Stoichiometry}

The reactive extraction of LA using a combination of extractants (TOA and TOMAC) and non-toxic diluent (soybean oil) is described by equilibrium reactions which take place between LA molecules and the molecules of extractants at the inter phase of aqueous and organic phase to form LAextractant complexes. When LA exists as in its undissociated form $(H A)$ in the aqueous phase, then the reaction of LA withTOA takes place through hydrogen bond formation and resulting into a complex (1:1) (TOA-LA) at low LA concentration.

$\underbrace{R_{3} N}_{\text {TOA }}+\underbrace{H A}_{\text {LA(un-dissociated form })} \leftrightarrow \underbrace{R_{3} N-H A}_{\text {TOA-LA complex }}$

The extracted acid which is extracted by extractants (amines) is not known as an acid for a longer time but as an ammonium salt and the extent of this ion pair association (alkyl ammonium cation and acid radical) quantify the degree of extraction.

When LA exists in its dissociated form $\left(H^{+}+A^{-}\right)$ in the aqueous phase then the complex is formed by ion-pair formation:

$\underbrace{R_{3} N}_{\text {TOA }}+\underbrace{H^{+}+A^{-}}_{\text {LA }(\text { dissociated form })} \leftrightarrow \underbrace{R_{3} N H^{+} A^{-}}_{\text {TOA-LA Complex }}$

Now, LA transportation takes place with the second water-insoluble extractant TOMAC (acts as an ion exchanger), quaternary ammonium salt obtained by methylation of mixed tri octyl/decylamine in which anion of LA is exchanged with an anion of quaternary ammonium salt (or chloride ion) to form oil soluble salts at neutral or slightly alkaline $\mathrm{pH}$, and reaction is given below [29].

$$
\begin{aligned}
& \underbrace{R_{4} N H^{+} X^{-}}_{\text {TOMAC }} \\
& \text { Chloride ion }
\end{aligned}
$$

It can be suggested that the synergistic combination of both extractants (TOA + TOMAC) can be led to the formation of various complexes as elucidated below:

$$
\begin{aligned}
& \underbrace{R_{3} N H^{+} A^{-}}_{\text {TOA-LA complex }}+\underbrace{R_{4} N H^{+} X^{-}}_{\text {TOMAC }} \leftrightarrow \\
& \underbrace{R_{3} N H^{+} A^{-} R_{4} N H^{+}}_{\text {LA-(TOA+TOMAC) complex }}+\underbrace{X^{-}}_{\text {Chloride ion }}
\end{aligned}
$$

or

$\underbrace{R_{4} N H^{+} A^{-}}_{\text {TOMAC-LA complex }}+\underbrace{R_{3} N}_{\text {TOA }} \leftrightarrow \underbrace{R_{3} N-R_{4} N H^{+} A^{-}}_{\text {LA-(TOA+TOMAC ) complex }}$

The LA distribution coefficient $\left(K_{\mathrm{D}}\right)$ is defined as the ratio of the concentration of acid (LA) in its all forms (such as complex, partition, and dimmers) in the organic phase to its concentration in its entirely existing form (such as non-dissociated and dissociated) in the aqueous phase [28].

LA distribution coefficient $\left(K_{\mathrm{D}}\right)=\frac{[\mathrm{HA}]_{\mathrm{org}}}{[\mathrm{HA}]_{\mathrm{aq}}}$

Where $[\mathrm{HA}]_{\text {org }}$. and $[\mathrm{HA}]_{\mathrm{aq}}$. is the concentration of LA in organic and aqueous phaserespectively. Distribution coefficient $\left(K_{\mathrm{D}}\right)$ depends on the following factors such as the characteristics of the diluent (act as non-reactive component) used, concentration of the extractant (act as a reactive component in the organic phase), and the number of carbon atoms present in the tertiary amines (usually used as an extractant) which further increases its extractability since the basicity and polarity of the amines increase with an increase in carbon chain length of the amines $[1,30]$. The key reaction in the LA reactive extraction is the reaction between solute (LA) and extractants (TOA and TOMAC) which produces a product (complex) with the lowest bond energy (less than $50 \mathrm{~kJ} / \mathrm{mol}$ ) so that solute is easily and economically back extracted for its again use [11]. The diluents are used in reactive extraction to increase the physical properties (surface tension, 
viscosity, and density) of these extractants by providing solvation and extraction power through giving specific interaction [31]. The transportation of solute concentration to the organic phase with respect to the sum of the solute concentration in both organic and aqueous phase is known as the degree of extraction $(\eta, \%)$ and is represented in the form of $K_{\mathrm{D}}$.

LA extraction efficiency $(\eta, \%)=\frac{K_{D} \times 100}{1+K_{D}}$

\subsection{Experimental Design}

LA distribution coefficient $\left(K_{\mathrm{D}}\right)$ was calculated by using the method of liquid-liquid extraction and its experimental run based on the experimental design received from Box - Behnken design (BBD) with the seven variables at three levels each using Design Expert 7.16 software (Statease Inc., Minneapolis, USA). The effect of seven independent process parameters (such as LA concentration in aqueous phase $\left(C_{1},[\mathrm{M}]\right)$, extractant ratio $(\alpha, \mathrm{v} / \mathrm{v})$, mixed extractants concentration $(\Psi, \% \mathrm{v} / \mathrm{v})$, phase ratio $(\Phi, \mathrm{v} / \mathrm{v})$, temperature $\left(T,{ }^{\circ} \mathrm{C}\right)$, stirring speed $(\omega, \mathrm{rpm})$, and contact time $(\tau,(\mathrm{min}))$ on the LA distribution coefficient $\left(K_{\mathrm{D}}\right)$ has been studied. The form of the original value of each factor (un-coded) and their corresponding levels (coded) has shown in Table 1. This experimental design includes 62 numbers of experiments using various combinations of several process parameters as shown in Table 2 .

Table 1: Range of Different Variables for the LA Distribution Coefficient in Coded and un-Coded form

\begin{tabular}{lclcccc}
\hline & Factors & & Process Parameters & Level & \\
\cline { 2 - 7 } & & & Coded variables & -1.00 & 0.00 & 1.00 \\
\cline { 2 - 7 } & $X_{1}$ & LA concentration & $C_{1},[\mathrm{M}]$ & 0.06 & 0.02 & 0.1 \\
Un-coded & $X_{2}$ & Extractant ratio & $\alpha$ & 0.5 & 1.25 & 2 \\
variables & $X_{3}$ & Mixed extractants concentration & $\Psi(\%, \mathrm{v} / \mathrm{v})$ & 10 & 20 & 30 \\
& $X_{4}$ & Phase ratio & $\Phi(\mathrm{v} / \mathrm{v})$ & 0.5 & 1.25 & 2 \\
& $X_{5}$ & Temperature & $T\left({ }^{\circ} \mathrm{C}\right)$ & 20 & 35 & 50 \\
& $X_{6}$ & Stirring speed & $\omega(\mathrm{rpm})$ & 50 & 125 & 200 \\
& $\mathrm{X}_{7}$ & Contact time & $\tau(\mathrm{min})$ & 60 & 90 & 120 \\
\hline
\end{tabular}

\subsection{Statistical Analysis and Optimization}

For the different interactions of any given two independent variables while keeping the other variables remain constant at the 0.00 value, response surface and contour figures were created. Such 3-Dsurface elucidates the useful detail information and perfect geometrical representation about the nature of the system inside the experimental design [32]. For gaining the large LA distribution coefficient $\left(K_{\mathrm{D}}\right)$, the optimum values of the various variables (such as initial LA concentration in the aqueous solution, extractant ratio, extractant concentration, phase ratio, stirring speed, temperature, and contact time) were determined within the experimental range. The experimental runs are being conducted using the model values of the variables which were generated by the optimization of the predicted values.

\section{Results and Discussions}

\subsection{Regression Model}

The following regression equations were generated as a result by using the multiple regressions (along with backward elimination regression with alpha to exist $=0.100)$ on experimental data. The quadratic model (in the coded forms) equation describes the role of each variable and their quadratic interaction on the LA distribution coefficient $\left(K_{\mathrm{D}}\right)$ as follows.

Distribution Coefficient $\left(\boldsymbol{K}_{\mathrm{D}}\right)=1.96-0.255 \times X_{1}-$ $0.0587 \times X_{2}+0.296 \times X_{3}-0.457 \times X_{4}-0.256 \times X_{5}-$ $0.129 \times X_{6}-0.06988 \times X_{7}+0.548 \times X_{1} \times X_{2}-0.06475 \times$ $-0.12 \times X_{1} \times X_{5}-0.339 \times X_{2} \times X_{4}-0.097 \times X_{2} \times X_{6}+0.132$ $\times X_{2} \times X_{7}+.074 \times X_{3} \times X_{4}-0.198 \times X_{3} \times X_{5}-0.096 \times X_{3} \times$ $X_{7}+0.152 \times X_{4} \times X_{7}+0.193 \times X_{5} \times X_{6}-0.077 \times X_{1}^{2}-0.175 \times$ $X_{2}^{2}-0.421 \times X_{3}^{2}-0.238 \times X_{4}^{2}-0.208 \times X_{5}^{2}-0.448 \times X_{6}^{2}$ 
Where, $X_{1}, X_{2}, X_{3}, X_{4}, X_{5}, X_{6}$, and $X_{7}$ represent initial LA concentration, extractant ratio, extractant concentration, phase ratio, temperature, stirring speed, and contact time, respectively. The quadric model equation (Eq.11) includes twentyfour terms which comprise seven linear terms, six quadric terms, and eleven two-factorial interactions. Out of these, the insignificant terms are those terms which have probability $(p)>$ Fischer tropsch coefficient $(f)$ value more than 0.05 in Table 3 . The values of the probability, $p$ $(p>f)$ were used as a tool to decide the importance of each coefficients. Lower the values of $p$, more the significant was the correlation with the corresponding coefficient. The values of coefficient of determination $\left(R^{2}\right)$ were satisfactory $\left(R^{2}>0.979\right)$ for the response $p \leq 0.05$ [33]. These values give a good agreement between the experimental observation and predicted values due to the difference between predicted $R^{2}$ (a measure of the value of the reduction in the variability of the response) and adjusted $R^{2}$ is very low (0.08). There was no lack of fit in the model equation $(p \geq$ 0.05). This model has good reliability, reproducibility, and accuracy since the coefficient of the variation (CV) has relatively small percentage value $(2.51 \%)$. The coefficient of the variation elucidates about the range to which data were spread. This model contains adequate precision 105.24 [34]. The three-D plots were generated for the different interaction of any two independent variables on the LA distribution coefficient $\left(K_{\mathrm{D}}\right)$, while keeping the values of the other variables constant at zero level.

\subsection{Distribution Coefficient $\left(K_{\mathrm{D}}\right)$}

The predicted model briefly elucidates the effect of the seven independent parameters on the LA distribution coefficient $\left(K_{\mathrm{D}}\right)$. The 3-D graphical representation of the response surfaces as illustrated in the figures $(1-8)$ needs to describe the interactive effect of the independent variables on the LA distribution coefficient $\left(K_{\mathrm{D}}\right)$. Each response curve signifies the variation in the level of two factors with the other five factors kept at zero level. The significant interactions between the independent variables have been observed as $X_{1} \& X_{4}, X_{1} \& X_{5}, X_{2} \& X_{4}, X_{2} \& X_{6}, X_{3} \& X_{4}, X_{3} \& X_{5}$, $X_{3} \& X_{7}$, and $X_{5} \& X_{6}$.

The effect of initial LA concentration $\left(C_{1},[\mathrm{M}]\right)$ and phase ratio $(\Phi, \mathrm{v} / \mathrm{v})$ on LA distribution coefficient $\left(K_{\mathrm{D}}\right)$ was shown in (Fig.1). Fig.1 has predicted that with the increase in the phase ratio and initial LA concentration, LA distribution coefficient decreases continuously. LA distribution coefficient $\left(K_{\mathrm{D}}\right)$ has been found to be decreased with the increase in the initial LA concentration irrespective of phase ratio because of attainment of saturation of the organic phase with the increase in the value of LA in the aqueous phase [35]. It may be due to the less availability of the extractants molecules in the organic phase at the high concentration $\left(C_{1}=0.1[\mathrm{M}]\right)$ of LA in the aqueous phase which further decreases the number of complexes formed between acid-extractant [27]. The LA distribution coefficient $\left(K_{\mathrm{D}}\right)$ decreases with an increase in phase ratio irrespective of LA concentration since the inadequate mixing (due to the improper ratio of the phases) of both phases (organic and aqueous phases) reduces the tendency of the complex formation which further decreases the interfacial rate of mass transfer [36]. The maximum value of LA distribution coefficient $\left(K_{\mathrm{D}}\right)$ was obtained for the low value of the phase ratio $(\Phi=0.5 \mathrm{v} / \mathrm{v})$ as well as LA concentration $\left(C_{1}=0.02[\mathrm{M}]\right)$.

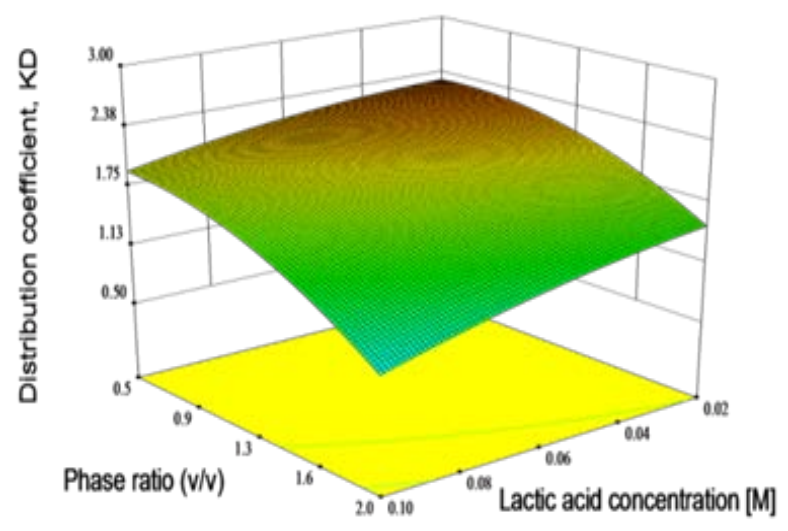

Fig. 1 Effect of the phase ratio and LA concentration on the LA distribution coefficient $\left(K_{\mathrm{D}}\right)$ 
Table 2: Experimental Design of the Coded Process Parameters for the LA Distribution Coefficient by Using Soybean Oil

\begin{tabular}{|c|c|c|c|c|c|c|c|}
\hline \multicolumn{8}{|c|}{ Coded Process Variables for Experiments } \\
\hline LA concentration & $\begin{array}{l}\text { Extractant } \\
\text { ratio }\end{array}$ & $\begin{array}{l}\text { Mixed extractants } \\
\text { concentration }\end{array}$ & $\begin{array}{l}\text { Phase } \\
\text { Ratio }\end{array}$ & Temperature & $\begin{array}{c}\begin{array}{c}\text { Stirring } \\
\text { speed }\end{array} \\
\end{array}$ & $\begin{array}{c}\text { Contact } \\
\text { time }\end{array}$ & $\begin{array}{c}\text { Distribution } \\
\text { coefficient }\end{array}$ \\
\hline$\left(X_{1}\right)$ & $\left(X_{2}\right)$ & $\left(X_{3}\right)$ & $\left(X_{4}\right)$ & $\left(X_{5}\right)$ & $\left(X_{6}\right)$ & $\left(X_{7}\right)$ & $K_{\mathrm{D}}$ \\
\hline 0 & -1 & -1 & 0 & 0 & -1 & 0 & 0.72 \\
\hline 0 & 0 & 1 & 1 & 0 & 0 & -1 & 1.22 \\
\hline-1 & -1 & 0 & -1 & 0 & 0 & 0 & 2.42 \\
\hline 0 & 0 & 0 & 0 & 0 & 0 & 0 & 1.94 \\
\hline-1 & 1 & 0 & 1 & 0 & 0 & 0 & 0.5 \\
\hline 1 & 1 & 0 & -1 & 0 & 0 & 0 & 2.58 \\
\hline 0 & 1 & 0 & 0 & -1 & 0 & -1 & 1.69 \\
\hline 0 & 0 & 1 & 1 & 0 & 0 & 1 & 1.19 \\
\hline 0 & 1 & 0 & 0 & -1 & 0 & 1 & 1.83 \\
\hline 0 & -1 & 1 & 0 & 0 & 1 & 0 & 1.25 \\
\hline 0 & -1 & -1 & 0 & 0 & 1 & 0 & 0.67 \\
\hline 0 & 0 & 1 & -1 & 0 & 0 & 1 & 1.69 \\
\hline 0 & 0 & 0 & -1 & -1 & 1 & 0 & 1.47 \\
\hline 0 & 0 & 0 & 0 & 0 & 0 & 0 & 1.99 \\
\hline-1 & 0 & -1 & 0 & -1 & 0 & 0 & 1.15 \\
\hline 0 & 0 & 0 & 0 & 0 & 0 & 0 & 1.97 \\
\hline 0 & 0 & -1 & 1 & 0 & 0 & 1 & 0.63 \\
\hline-1 & 0 & 0 & 0 & 0 & 1 & 1 & 1.48 \\
\hline 1 & 0 & 0 & 0 & 0 & -1 & -1 & 1.4 \\
\hline 0 & 0 & 0 & -1 & -1 & -1 & 0 & 2.13 \\
\hline 0 & 1 & 1 & 0 & 0 & -1 & 0 & 1.37 \\
\hline 0 & 1 & -1 & 0 & 0 & -1 & 0 & 0.79 \\
\hline 0 & 0 & -1 & -1 & 0 & 0 & 1 & 1.43 \\
\hline-1 & -1 & 0 & 1 & 0 & 0 & 0 & 2.27 \\
\hline 0 & 0 & 0 & 1 & -1 & 1 & 0 & 0.53 \\
\hline 0 & 0 & -1 & -1 & 0 & 0 & -1 & 1.68 \\
\hline 0 & 0 & 0 & 0 & 0 & 0 & 0 & 1.95 \\
\hline 0 & 0 & 0 & 0 & 0 & 0 & 0 & 1.98 \\
\hline 1 & -1 & 0 & -1 & 0 & 0 & 0 & 0.8 \\
\hline 1 & 0 & -1 & 0 & -1 & 0 & 0 & 0.9 \\
\hline 1 & 0 & 1 & 0 & -1 & 0 & 0 & 1.89 \\
\hline 0 & 0 & 0 & -1 & 1 & -1 & 0 & 1.23 \\
\hline 1 & -1 & 0 & 1 & 0 & 0 & 0 & 0.58 \\
\hline 0 & -1 & 0 & 0 & -1 & 0 & -1 & 2.1 \\
\hline-1 & 0 & 0 & 0 & 0 & 1 & -1 & 1.64 \\
\hline 1 & 0 & 1 & 0 & 1 & 0 & 0 & 0.74 \\
\hline 0 & 0 & -1 & 1 & 0 & 0 & -1 & 0.28 \\
\hline 0 & 0 & 0 & 1 & -1 & -1 & 0 & 1.18 \\
\hline-1 & 1 & 0 & -1 & 0 & 0 & 0 & 1.82 \\
\hline 0 & -1 & 1 & 0 & 0 & -1 & 0 & 1.29 \\
\hline-1 & 0 & 0 & 0 & 0 & -1 & -1 & 1.9 \\
\hline 0 & 1 & -1 & 0 & 0 & 1 & 0 & 0.35 \\
\hline 0 & 0 & 0 & 1 & 1 & 1 & 0 & 0.43 \\
\hline-1 & 0 & 0 & 0 & 0 & -1 & 1 & 1.72 \\
\hline 0 & -1 & 0 & 0 & 1 & 0 & 1 & 1.21 \\
\hline-1 & 0 & 1 & 0 & -1 & 0 & 0 & 2.14 \\
\hline 0 & 1 & 1 & 0 & 0 & 1 & 0 & 0.94 \\
\hline 0 & -1 & 0 & 0 & 1 & 0 & -1 & 1.59 \\
\hline 1 & 0 & 0 & 0 & 0 & -1 & 1 & 1.27 \\
\hline 0 & 1 & 0 & 0 & 1 & 0 & -1 & 1.19 \\
\hline 0 & -1 & 0 & 0 & -1 & 0 & 1 & 1.71 \\
\hline 0 & 0 & 0 & -1 & 1 & 1 & 0 & 1.31 \\
\hline 1 & 0 & -1 & 0 & 1 & 0 & 0 & 0.54 \\
\hline 1 & 0 & 0 & 0 & 0 & 1 & 1 & 0.98 \\
\hline 1 & 0 & 0 & 0 & 0 & 1 & -1 & 1.12 \\
\hline 0 & 1 & 0 & 0 & 1 & 0 & 1 & 1.33 \\
\hline-1 & 0 & 1 & 0 & 1 & 0 & 0 & 1.46 \\
\hline 0 & 0 & 1 & -1 & 0 & 0 & -1 & 2.33 \\
\hline 1 & 1 & 0 & 1 & 0 & 0 & 0 & 0.82 \\
\hline 0 & 0 & 0 & 1 & 1 & -1 & 0 & 0.27 \\
\hline-1 & 0 & -1 & 0 & 1 & 0 & 0 & 1.27 \\
\hline 0 & 0 & 0 & 0 & 0 & 0 & 0 & 1.98 \\
\hline
\end{tabular}


Table 3: ANOVA for Response Surface Reduced Quadratic Model Analysis of Variance

\begin{tabular}{|c|c|c|c|c|c|c|}
\hline Source & $\begin{array}{l}\text { Sum of } \\
\text { Squares }\end{array}$ & $\begin{array}{l}\text { Degree of } \\
\text { freedom } \\
\text { (DOF) }\end{array}$ & $\begin{array}{l}\text { Mean } \\
\text { Square }\end{array}$ & $f$-value & $\begin{array}{c}\text { p-value } \\
\text { Prob. }>\text { F }\end{array}$ & \\
\hline Model & 20.5 & 24 & 0.856 & 736.19 & $<0.0001$ & Significant \\
\hline \multicolumn{7}{|l|}{ LA } \\
\hline Concentration $\left(\mathrm{X}_{1}\right)$ & 1.56 & 1 & 1.566 & 1346.7 & $<0.0001$ & \\
\hline Extractant ratio $\left(X_{2}\right)$ & 0.08 & 1 & 0.0826 & 71.082 & $<0.0001$ & \\
\hline \multicolumn{7}{|l|}{ Mixed extractants } \\
\hline Concentration $\left(X_{3}\right)$ & 2.10 & 1 & 2.105 & 1810.21 & $<0.0001$ & \\
\hline Phase ratio $\left(X_{4}\right)$ & 5.02 & 1 & 5.02 & 4319.75 & $<0.0001$ & \\
\hline Temperature $\left(\mathrm{X}_{5}\right)$ & 1.58 & 1 & 1.581 & 1359.11 & $<0.0001$ & \\
\hline Stirring speed $\left(X_{6}\right)$ & 0.39 & 1 & 0.399 & 343.37 & $<0.0001$ & \\
\hline Contact time $\left(\mathrm{X}_{7}\right)$ & 0.11 & 1 & 0.112 & 100.730 & $<0.0001$ & \\
\hline$\left(\mathrm{X}_{1}\right) \cdot\left(X_{2}\right)$ & 2.40 & 1 & 2.409 & 2070.83 & $<0.0001$ & \\
\hline$\left(\mathrm{X}_{1}\right) \cdot\left(X_{4}\right)$ & 0.03 & 1 & 0.033 & 28.832 & $<0.0001$ & \\
\hline$\left(X_{1}\right) \cdot\left(X_{5}\right)$ & 0.12 & 1 & 0.114 & 98.204 & $<0.0001$ & \\
\hline$\left(X_{2}\right) \cdot\left(X_{4}\right)$ & 0.92 & 1 & 0.918 & 789.14 & $<0.0001$ & \\
\hline$\left(X_{2}\right) \cdot\left(X_{6}\right)$ & 0.07 & 1 & 0.075 & 65.248 & $<0.0001$ & \\
\hline$\left(X_{2}\right) \cdot\left(X_{7}\right)$ & 0.13 & 1 & 0.138 & 119.37 & $<0.0001$ & \\
\hline$\left(X_{3}\right) \cdot\left(X_{4}\right)$ & 0.04 & 1 & 0.043 & 37.658 & $<0.0001$ & \\
\hline$\left(X_{3}\right) \cdot\left(X_{5}\right)$ & 0.31 & 1 & 0.315 & 270.96 & $<0.0001$ & \\
\hline$\left(X_{3}\right) \cdot\left(X_{7}\right)$ & 0.07 & 1 & 0.073 & 63.048 & $<0.0001$ & \\
\hline$\left(X_{4}\right) \cdot\left(X_{7}\right)$ & 0.18 & 1 & 0.184 & 158.88 & $<0.0001$ & \\
\hline$\left(X_{5}\right) \cdot\left(X_{6}\right)$ & 0.30 & 1 & 0.300 & 258.15 & $<0.0001$ & \\
\hline$\left(X_{1}\right)^{2}$ & 0.08 & 1 & 0.0830 & 71.378 & $<0.0001$ & \\
\hline$\left(X_{2}\right)^{2}$ & 0.42 & 1 & 0.421 & 71.37 & $<0.0001$ & \\
\hline$\left(X_{3}\right)^{2}$ & 2.45 & 1 & 2.452 & 362.51 & $<0.0001$ & \\
\hline$\left(X_{4}\right)^{2}$ & 0.78 & 1 & 0.784 & 2108.42 & $<0.0001$ & \\
\hline$\left(X_{5}\right)^{2}$ & 0.60 & 1 & 0.6009 & 674.22 & $<0.0001$ & \\
\hline$\left(X_{6}\right)^{2}$ & 2.78 & 1 & 2.785 & 516.65 & $<0.0001$ & \\
\hline Residual & 0.04 & 37 & 0.0011 & & & \\
\hline Lack of Fit & 0.04 & 32 & 0.00129 & 4.437 & $0.0512^{\mathrm{a}}$ & $\begin{array}{l}\text { Non- } \\
\text { significant }\end{array}$ \\
\hline Pure Error & 0.00 & 5 & 0.00029 & & $<0.0001$ & \\
\hline Cor. Total & 20.5 & 61 & 0.856 & & $<0.0001$ & \\
\hline \multicolumn{4}{|c|}{ Standard deviation $=0.034$} & \multicolumn{2}{|c|}{$\mathrm{R}^{2}=0.9979$} & \\
\hline \multicolumn{4}{|c|}{ Mean $=1.35$} & \multicolumn{2}{|c|}{ Adjusted $R^{2}=0.979$} & \\
\hline \multicolumn{4}{|c|}{ Coefficient of variation $=2.511$} & \multicolumn{2}{|c|}{ Predicted $R^{2}=0.968$} & \\
\hline \multicolumn{4}{|c|}{ Press $=0.242$} & \multicolumn{2}{|c|}{ Adequate precision $=105.24$} & \\
\hline
\end{tabular}

The effect of initial LA concentration $\left(C_{1},[\mathrm{M}]\right)$ and temperature $\left(T,{ }^{\circ} \mathrm{C}\right)$ on the LA distribution coefficient $\left(K_{\mathrm{D}}\right)$ has shown in Fig.2. It has been elucidated in Fig. 2 that the LA distribution coefficient $\left(K_{\mathrm{D}}\right)$ decreases with an increase in both the temperature and initial LA concentration in the aqueous phase, respectively. With the rise in temperature, the LA distribution coefficient $\left(K_{\mathrm{D}}\right)$ decreases at fast rate for the high value of the LA concentration $\left(C_{1}=0.1[\mathrm{M}]\right)$, since with rise in the temperature the increment in the thermal energy of the solution (i.e. increasing randomness between the molecules) which is responsible for the very less interactions between extractants (such as TOA and TOMAC) and solute (LA) molecules. During the formation of complex, system should have very less entropy or it should be more and more ordered but, in this case, it is disturbed due to the increased system entropy with the continuous increment in extraction system temperature which further disturbed the formation of the complexes [37]. At high temperature $\left(T=50^{\circ} \mathrm{C}\right)$, the decrement in LA distribution coefficient $\left(K_{\mathrm{D}}\right)$ is more with respect to low temperature $\left(T=20^{\circ} \mathrm{C}\right)$ with the increase in the initial lactic LA concentration. The LA distribution coefficient $\left(K_{\mathrm{D}}\right)$ decreases with the rise in initial LA concentration due to the presence of saturation of organic phase with LA molecules at a high value of concentration [38]. 


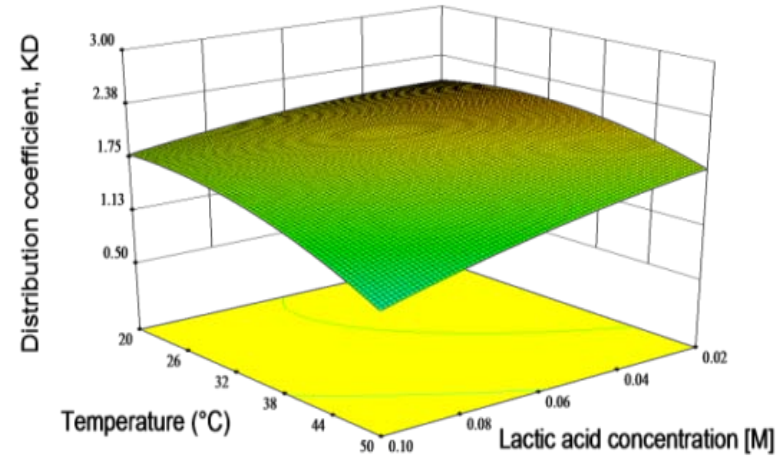

Fig.2 Effect of the temperature and LA concentration on the LA distribution coefficient $\left(K_{\mathrm{D}}\right)$

The interaction between phase ratio $(\Phi, \mathrm{v} / \mathrm{v})$ and extractant ratio $(\alpha, \mathrm{v} / \mathrm{v})$ has shown in Fig.3. It has been explained in Fig. 3 that at the low value of phase ratio $(\Phi=0.5 \mathrm{v} / \mathrm{v})$, the LA distribution coefficient $\left(K_{\mathrm{D}}\right)$ increase with the rise in the extractant ratio $(\alpha, v / v)$ since as the value of extractant ratio increases, the amount of TOMAC (quaternary amine) decreases with respect to TOA (tertiary amine), which is very viscous (1500 mpa.s at a temperature of $30 \mathrm{C}$ ) in nature and creates a hindrance for the interfacial mass transfer between the phases. TOMAC having an organic cation along with the chloride ion which makes it possible to work as an anion exchanger reagent [37].

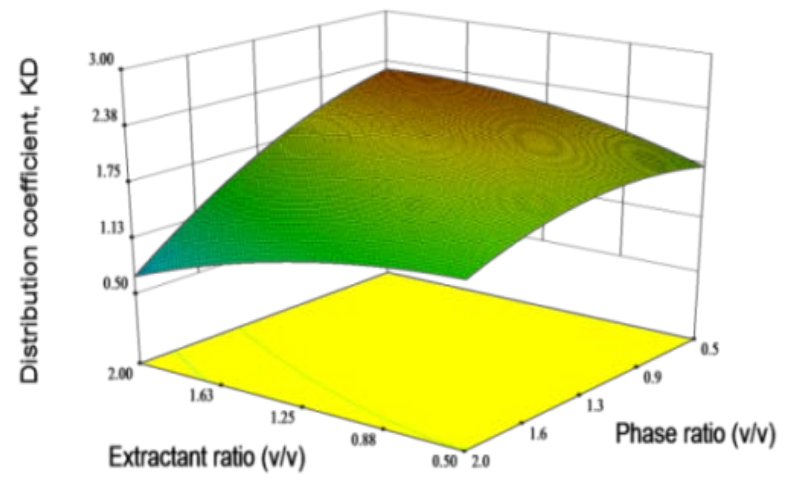

Fig.3 Effect of the phase ratio and extractant ratio on the LA distribution coefficient $\left(K_{\mathrm{D}}\right)$

Alone TOMAC does not give high LA distribution coefficient $\left(K_{\mathrm{D}}\right)$ since it is very viscous in nature which further limits rate of mass transfer but due to the synergetic effect of the extractants (TOMAC+TOA) and the presence of natural solvent (also has good solvation for the complex), it gives high value of LA distribution coefficient $\left(K_{\mathrm{D}}\right)$ [17]. At high value of phase ratio $(\Phi=2$ $\mathrm{v} / \mathrm{v})$, the value of LA distribution coefficient $\left(K_{D}\right)$ decreases with an increase in the extractant ratio since here phase ratio is dominating not the extractant ratio. These extractants (TOA and TOMAC) are toxic in nature to microbes so they should be mixed with the natural solvent (soybean oil) which helps in both reducing the toxicity as well as increase the solvation for the complex (acid-extractant) and also in making the system eco-friendly [39]. The maximum value of LA distribution coefficient $\left(K_{\mathrm{D}}\right)$ has been gained for low value of phase ratio $(\Phi=0.5 \mathrm{v} / \mathrm{v})$ and extractant ratio value (for $\alpha=1.6$ (approximate) $\mathrm{v} / \mathrm{v})$.

Fig.4 shows the interaction between extractant ratio $(\Phi, \mathrm{v} / \mathrm{v})$ and stirring speed $(\omega, \mathrm{rpm})$. It is explained from Fig.4 that at high extractant ratio $(\Phi=2 \mathrm{v} / \mathrm{v})$, the LA distribution coefficient $\left(K_{\mathrm{D}}\right)$ increases with an increase in the stirring speed upto-the optimum value ( $\omega=105$ (approximate) $\mathrm{rpm})$, then decreases since with an increase in the stirring speed, because of the disturbance in the interfacial layer at the interface increases more with the stirring speed which further reduces the thickness of the layer and increases the rate of transfer of LA molecules from aqueous phase to the organic phase [28].

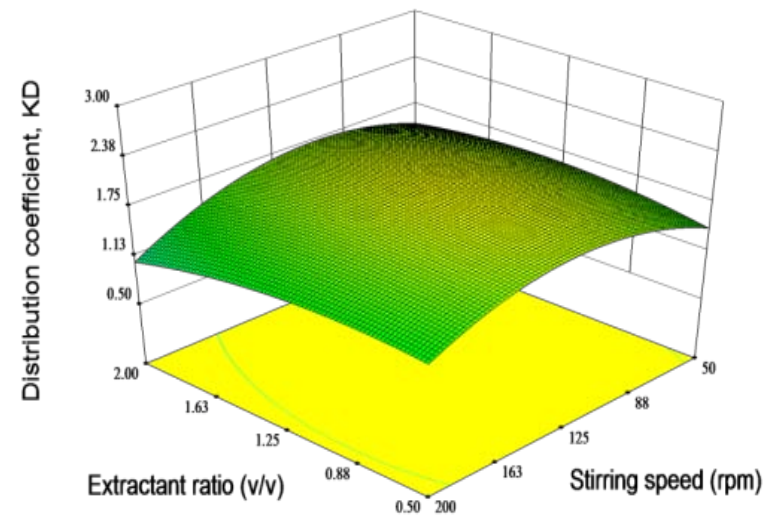

Fig.4 Effect of the stirring speed and extractant ratio on the LA distribution coefficient $\left(K_{D}\right)$

Beyond the optimum stirring speed $(\omega=105$ (approximate) rpm), the LA distribution coefficient $\left(K_{\mathrm{D}}\right)$ decreases with increase in stirring 
speed because of the large displacement of extractant molecules from the interface due to a high level of turbulence hence very fewer molecules of extractants are present at the interface to form various complexes (acid-extractant) [40]. At high stirring speed ( $\omega=200 \mathrm{rpm})$, the value of LA distribution coefficient $\left(K_{\mathrm{D}}\right)$ changes very less and levelled-off for further increase in the extractant ratio but at low stirring speed $(\omega=50$ $\mathrm{rpm})$, the value of LA distribution coefficient $\left(K_{\mathrm{D}}\right)$ first increases up to extractant ratio value (for $\alpha=$ 1.3 (approximate) $\mathrm{v} / \mathrm{v}$ ) then reduces with further increase in the value of extractant ratio since with the rise in extractant ratio the loading rate of the extractants reduces [41]. The maximum value of LA distribution coefficient $\left(K_{D}\right)$ has been obtained at stirring speed of 105 (approximate) rpm and extractant ratio value (for $\alpha=1.3$ (approximate) $\mathrm{v} / \mathrm{v})$.

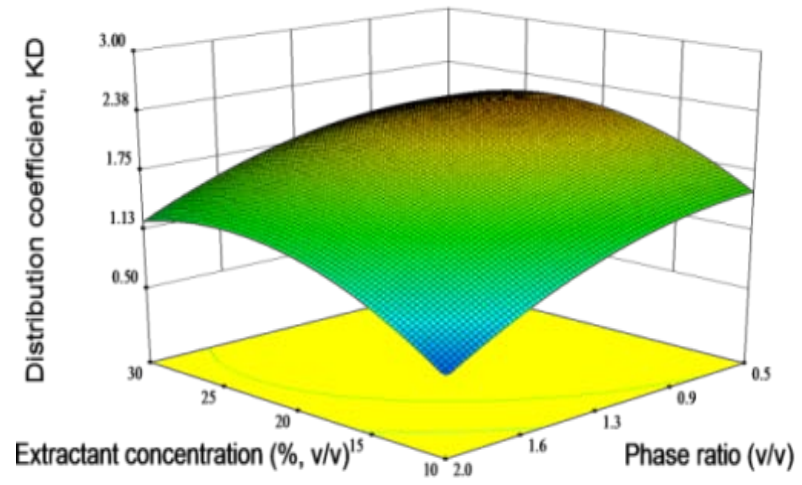

Fig.5 Effect of the phase ratio and mixed extractants concentration on the LA distribution coefficient $\left(K_{\mathrm{D}}\right)$

Fig. 5 shows the interaction between the phase ratio $(\Phi, \mathrm{v} / \mathrm{v})$ and mixed extractants concentration $(\Psi$, $\% \mathrm{v} / \mathrm{v})$. Fig. 5 shows that at high values of phase ratio $(\Phi=2 \mathrm{v} / \mathrm{v})$, with the increase in the mixed extractant concentration, the value of LA distribution coefficient $\left(K_{\mathrm{D}}\right)$ increases but levelled off at high mixed extractants concentration because the concentration for the formation of complex (acid-extractant) also increases with the increase in the mixed extractants concentration [12]. At low phase ratio ( $\Phi=0.5 \mathrm{v} / \mathrm{v})$, the value of LA distribution coefficient $\left(K_{\mathrm{D}}\right)$ first increases up to the maximum value with an increase in mixed extractants concentration up to $(\Psi=25 \%$ $\mathrm{v} / \mathrm{v}$ (approximate)) then decreases since with increasing in extractant concentration, the extractability of the extractant increases which favors the rate of formation of complexes [35]. The LA distribution coefficient $\left(K_{D}\right)$ reduces for high extractant concentration, may be due to less availability of the solute molecules at a low value of phase ratio. The other plausible reason may be due to the high viscosity of the organic phase increases the interfacial resistance between the phases which further reduces the rate of mass transfer of LA molecules from the aqueous phase to the organic phase [36]. The maximum value of LA distribution coefficient $\left(K_{\mathrm{D}}\right)$ has been obtained at low value of phase ratio $(\Phi=0.5 \mathrm{v} / \mathrm{v})$ and mixed extractants concentration $(\Psi=25 \% \mathrm{v} / \mathrm{v}$ (approximate)). The effect of mixed extractants concentration $(\Psi, \mathrm{v} / \mathrm{v})$ and temperature $\left(T,{ }^{\circ} \mathrm{C}\right)$ on LA distribution coefficient $\left(K_{\mathrm{D}}\right)$ was shown in Fig.6.

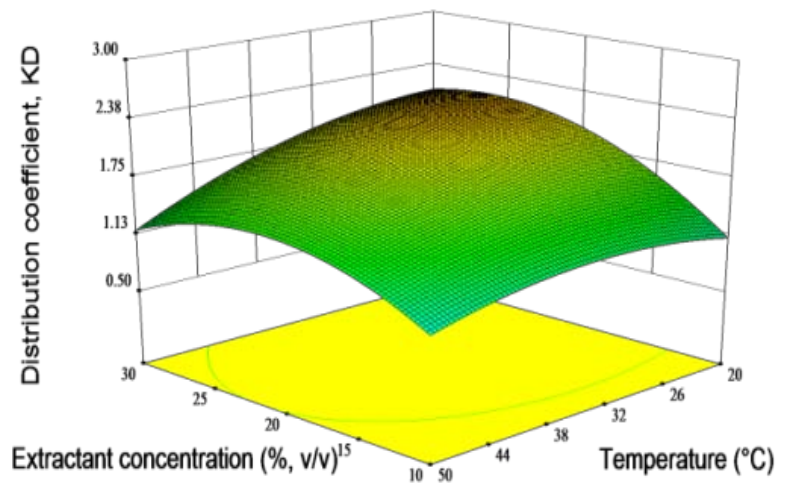

Fig.6 Effect of the temperature and mixed extractants concentration on the LA distribution coefficient $\left(K_{\mathrm{D}}\right)$

Fig.6 elucidates that with an increase in extraction the temperature, the value of LA distribution coefficient $\left(K_{\mathrm{D}}\right)$ decreases irrespective of the mixed extractants concentration but this decrease is sharp at high mixed extractants concentration ( $\Psi$ $=30 \% \mathrm{v} / \mathrm{v}$ ) and smooth at low mixed extractants concentration $(\Psi=10 \% \mathrm{v} / \mathrm{v})$ due to the high viscosity of the organic phase at high mixed extractants concentration [26]. At high temperature $\left(T=50^{\circ} \mathrm{C}\right)$, the LA distribution coeff icient $\left(K_{\mathrm{D}}\right)$ increases with an increase in the mixed extractants concentration but less than at low temperature ( $T=$ $20^{\circ} \mathrm{C}$ ) due to the dominance of the temperature factor is more than the mixed extractants concentration. At low temperature $\left(T=20^{\circ} \mathrm{C}\right)$, with 
the increase in the mixed extractants concentration, the value of LA distribution coefficient $\left(K_{D}\right)$ increases up to a maximum value then leveled-off for high values of mixed extractants concentration. It may be due to the non-polar nature of the TOA and itself a poor solvating media for the polar complex [38]. The maximum value of the LA distribution coefficient $\left(K_{\mathrm{D}}\right)$ was obtained for the mixed extractants concentration $(\Psi=26 \% \mathrm{v} / \mathrm{v}$ (approximate) $)$ and extraction temperature $(T=$ $26^{\circ} \mathrm{C}$ (approximate)). The effect of mixed extractants concentration $(\Psi, \mathrm{v} / \mathrm{v})$ and contact time $(\tau, \min )$ on LA distribution coefficient $\left(K_{D}\right)$ has shown in Fig.7.

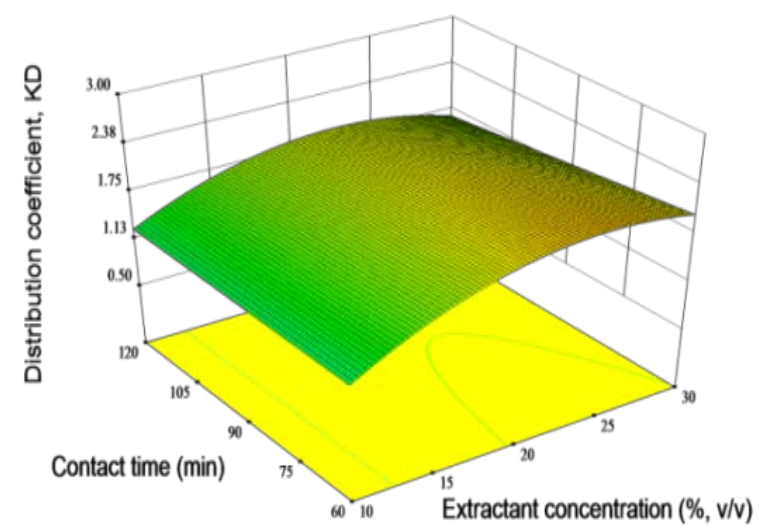

Fig.7 Effect of the contact time and mixed extractants concentration on the LA distribution coefficient $\left(K_{\mathrm{D}}\right)$

Fig.7 illustrates that for high values of mixed extractants concentration $(\Psi=30 \% \mathrm{v} / \mathrm{v})$, the value of LA distribution coefficient $\left(K_{\mathrm{D}}\right)$ decreases with an increase in the contact time. It may be due to the low contact time (60 min (approximate)) is adequate for the efficient and effective mixing of both the phases which further leading to the high rate of interfacial mass transfer [36]. With the increase in contact time, the value LA distribution coefficient $\left(K_{\mathrm{D}}\right)$ decreases which may be due to the beginning of the back extraction for higher values of contact time. The synergistic effect of the mixed extractants (TOMAC+TOA) gives higher values of the LA distribution coefficient $\left(K_{\mathrm{D}}\right)$ than the individual ones which make extraction process more and more effective and efficient [17, 37]. At the low values of mixed extractants concentration $(\Psi=10 \% \mathrm{v} / \mathrm{v})$, the LA distribution coefficient $\left(K_{\mathrm{D}}\right)$ does not change so much or remains constant with the contact time because the dominating factor is mixed extractant concentration, not the contact time and therefore further increment in contact time does not have any influence on the LA distribution coefficient. The maximum value of LA distribution coefficient $\left(K_{\mathrm{D}}\right)$ was obtained at low contact time $(\tau=60 \mathrm{~min})$ and high mixed extractants concentration $(\Psi=27 \% \quad \mathrm{v} / \mathrm{v}$ (approximate)). The effect of extraction temperature $\left(T, 26^{\circ} \mathrm{C}\right)$ and stirring speed $(\omega, \mathrm{rpm})$ on the LA distribution coefficient $\left(K_{D}\right)$ has elucidated in Fig.8.

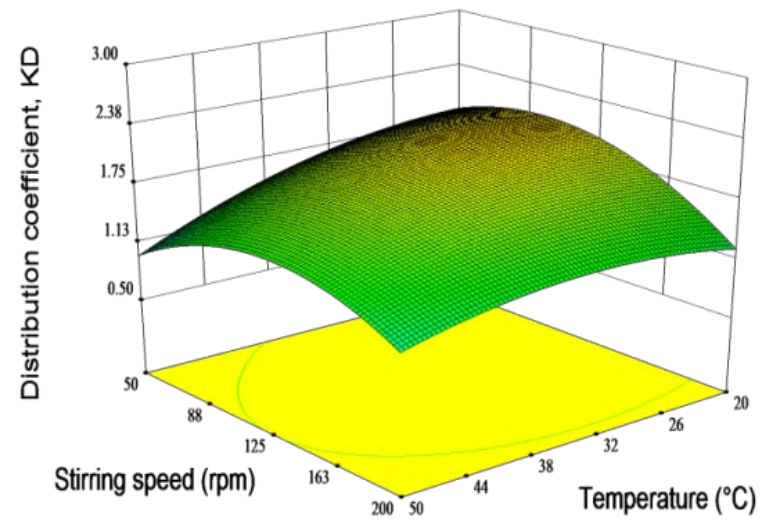

Fig. 8 Effect of the stirring speed and temperature on the LA distribution coefficient $\left(K_{\mathrm{D}}\right)$

Fig. 8 has been explained that LA distribution coefficient $\left(K_{D}\right)$ increases with the increase in the stirring speed up-to an optimum value then reduces because the high stirring speed responsible for the poor interaction between the extractant molecules and solute molecules which further resulting into the formation of a weak or unstable (means dissociated at very fast rate) acid-extractant complex and hence, responsible for the poor values of LA distributions [42]. With the decrease in the temperature, the value of the LA distribution coefficient $\left(K_{D}\right)$ increases since the molecules of the solution becomes more and more ordered (means decreasing in entropy of the solution) with reducing the temperature which will further helps for strong interaction between acid-extractant [29]. The maximum value of LA distribution coefficient was achieved for the optimum values of extraction temperature $\left(T=26^{\circ} \mathrm{C}\right.$ (approximate)) and stirring speed $(\omega=105 \mathrm{rpm}$ (approximate)). 
The optimized values of various process parameters are as follows: $0.02[\mathrm{M}]$ initial LA concentration $\left(C_{1}\right), 0.5(\mathrm{v} / \mathrm{v})$ extractant ratio $(\alpha)$, $28.66 \%(\mathrm{v} / \mathrm{v})$ mixed extractants concentration $(\Psi)$, $2(\mathrm{v} / \mathrm{v})$ phase ratio $(\Phi), 27^{\circ} \mathrm{C}$ temperature $(T), 102$ rpm stirring speed $(\omega)$, and 63 min contact time $(\tau)$. After the process parameter optimization using response surface methodology, the optimized value of LA distribution coefficient $\left(K_{\mathrm{D}}\right)$ have been achieved 2.51. The final LA extraction efficiency under the obtained optimized process conditions was found to be near $71.5 \%$. The synergism of these extractants (TOMAC+TOA) has been provided the higher LA extraction efficiency than their individual applications during the extraction process [17, 37]. This extraction efficiency has been found better than the individual extractants $[43,44]$.

Table 4: Thermodynamic Parameters of Lactic Acid Reactive Extraction

\begin{tabular}{|c|c|c|c|c|c|c|c|}
\hline Extractants & $\mathrm{T}(\mathrm{K})$ & $1000 / \mathrm{T}\left(\mathrm{K}^{-1}\right)$ & $D$ & $\log K_{\mathrm{D}}$ & $\Delta H\left(\mathrm{~kJ} \mathrm{~mol}^{-1}\right)$ & $\Delta G\left(\mathrm{~kJ} \mathrm{~mol}^{-1}\right)$ & $\Delta S\left(\mathrm{~J} \mathrm{~mol}^{-1}\right)$ \\
\hline \multirow{5}{*}{ TOA } & 293.15 & 3.41 & 1.515 & 0.180 & \multirow[t]{5}{*}{-6.045} & \multirow[t]{5}{*}{-1.095} & \multirow[t]{5}{*}{-16.885} \\
\hline & 298.15 & 3.35 & 1.526 & 0.183 & & & \\
\hline & 303.15 & 3.29 & 1.492 & 0.173 & & & \\
\hline & 308.15 & 3.24 & 1.410 & 0.149 & & & \\
\hline & 313.15 & 3.19 & 1.283 & 0.108 & & & \\
\hline \multirow{5}{*}{ TOMAC } & 293.15 & 3.41 & 0.252 & -0.598 & \multirow[t]{5}{*}{-30.945} & \multirow[t]{5}{*}{2.965} & \multirow[t]{5}{*}{-115.68} \\
\hline & 298.15 & 3.35 & 0.263 & -0.58 & & & \\
\hline & 303.15 & 3.29 & 0.228 & -0.642 & & & \\
\hline & 308.15 & 3.24 & 0.147 & -0.832 & & & \\
\hline & 313.15 & 3.19 & 0.119 & -925 & & & \\
\hline \multirow{5}{*}{$\begin{array}{c}\text { TOA } \\
+ \text { TOMAC }\end{array}$} & 293.15 & 3.41 & 2.548 & 0.406 & \multirow[t]{5}{*}{-3.567} & \multirow[t]{5}{*}{-2.329} & \multirow[t]{5}{*}{-4.223} \\
\hline & 298.15 & 3.35 & 2.560 & 0.408 & & & \\
\hline & 303.15 & 3.29 & 2.525 & 0.402 & & & \\
\hline & 308.15 & 3.24 & 2.443 & 0.387 & & & \\
\hline & 313.15 & 3.19 & 2.316 & 0.364 & & & \\
\hline
\end{tabular}

\subsection{Effect of the Temperature on the LA Reactive Extraction}

Temperature is considered as one of the most important process parameter which has a direct influence on the equilibrium of liquid-liquid extraction process. By keeping all other process parameters constant, the effect of temperature on the LA extraction using the synergistic effect of the mixed extractants (TOA and TOMAC) has been studied from 293.15 to $313.15 \mathrm{~K}$ in a temperature-controlled shaker. The following thermodynamic properties (change in enthalpy $(\Delta H)$, entropy $(\Delta S)$, and Gibbs free energy $(\Delta G))$ have been calculated by using the following equations $[45,46]$.

$$
\begin{aligned}
& \frac{\Delta \log K_{D}}{\Delta \frac{1}{T}}=\frac{-\Delta H}{2.303 R} \\
& \Delta G=\Delta H-T \Delta S
\end{aligned}
$$

Where $\mathrm{R}$ the universal gas constant $\left(8.314 \mathrm{Jmol}^{-1} \mathrm{~K}^{-1}\right)$ and $K_{\mathrm{D}}$ is the LA distribution coefficient. The graph between $\log K_{\mathrm{D}}$ vs $1000 / \mathrm{T}$ is 
linear (as shown in Fig.9). The value of the change in enthalpy $(\Delta H)$ is found to be negative (as shown in Table 4) for LA extraction with TOA, TOMAC, and (TAO+TOMAC) which elucidates that the LA reactive extraction process is exothermic in nature. The determined values of $\Delta H, \Delta S$ and $\Delta G$ for the LA reactive extraction have elucidated in Table 4. The value of Gibbs free energy for the mixed extractants system (TOA+TOMAC) is negative which indicates the feasibility of the extraction process and also tells about the spontaneity of the extraction reaction. The negative value of entropy confirms that the nature/state of the molecules within the system is more and more ordered during the extraction process $[45,46]$.

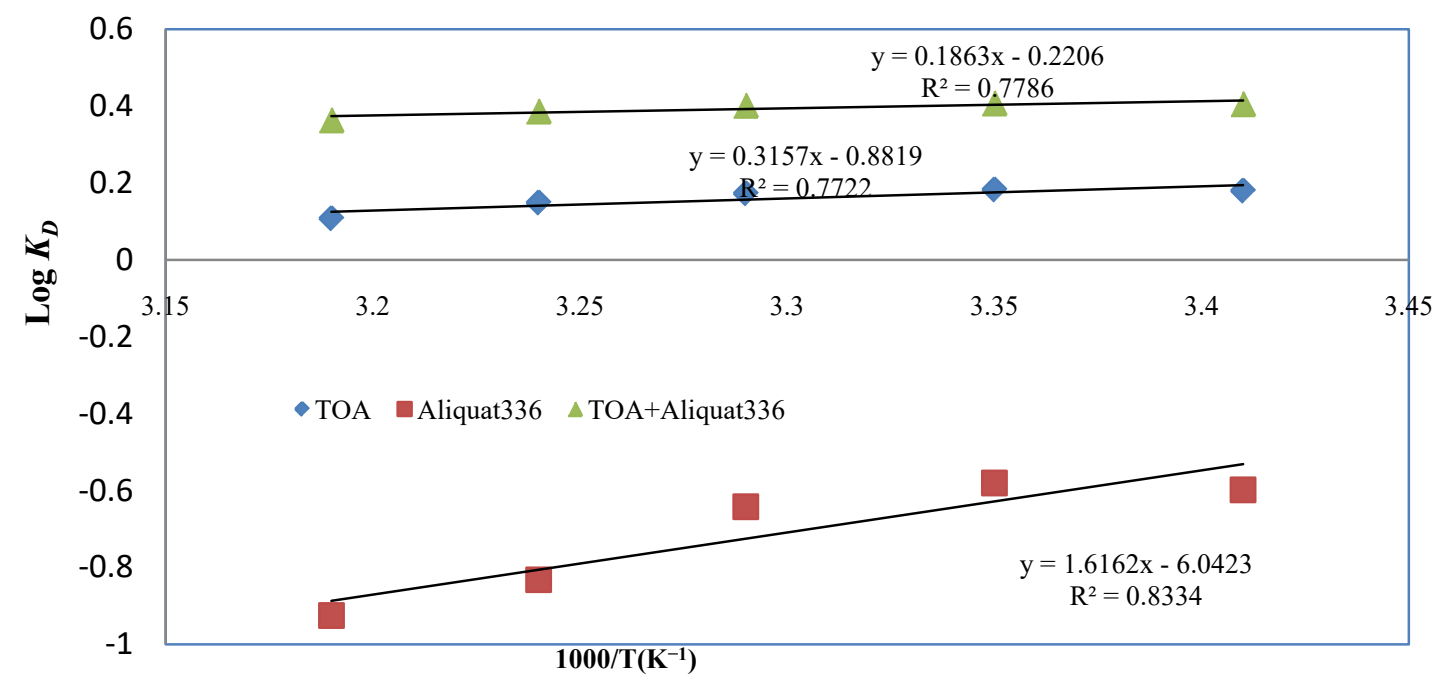

Fig.9 Effect of temperature on reactive extraction of LA with the mixed extractants (TOA+ TOMAC) [LA concentration $\left(C_{1}\right)=0.02[\mathrm{M}]$, extractant ratio $(\alpha)=0.5(\mathrm{v} / \mathrm{v})$, extraction concentration $(\Psi)=28.66 \%(\mathrm{v} / \mathrm{v})$, phase ratio $(\Phi)=2(\mathrm{v} / \mathrm{v})$, stirring speed $(\omega)=102 \mathrm{rpm}$, and agitation time $(\tau)=63 \mathrm{~min}]$

\section{Conclusions}

The numerical optimization technique has been used to optimize the quadratic model equation (Eq.11) for gaining the optimum value of the process parameters which further used to obtain the maximum value of LA distribution coefficient $\left(K_{\mathrm{D}}\right)$. The maximum value of LA distribution coefficient $\left(K_{\mathrm{D}}\right)$ was found 2.51 for the optimum values of various process parameters such as 0.02 [M] initial lactic acid concentration $\left(C_{1}\right), 0.5(\mathrm{v} / \mathrm{v})$ extractant ratio $(\alpha), 28.66 \%(\mathrm{v} / \mathrm{v})$ mixed extractants concentration $(\Psi), 2(\mathrm{v} / \mathrm{v})$ phase ratio $(\Phi), 27^{\circ} \mathrm{C}$ temperature $(T), 102 \mathrm{rpm}$ stirring speed $(\omega)$, and 63 min contact time $(\tau)$. The maximum LA extraction efficiency has been obtained $71.5 \%$ under these optimized conditions. The synergistic effect of the mixed extractants (TOMAC+TOA) has shown the higher value of LA distribution coefficient than the individual extractants. The problem of toxicity in the LA reactive extraction can be reduced either by the use of triglycerides of fatty acids (natural diluents) such as soybean oil along with the extractants or a combination of non-toxic extractant-diluent. The results obtained from this current investigation will be very useful for the design of reactive extraction unit for the separation of lower carboxylic acids from the real fermentation broth as well as from the dilute waste streams of various fermented based industries. Further, research will be need for the better insights of the synergistic extraction mechanisms during the separation of lower carboxylic acids.

\section{ACKNOWLEDGMENT}

Authors are thankful to Sant Longowal Institute of Engineering and Technology, Longowal India for providing the lab facilities and all necessary help to perform this research work. 


\section{Symbols}

$\begin{array}{ll}\text { DOF } & \text { Degree of freedom } \\ \text { CV } & \text { Coefficient of variation } \\ \text { Std. Dev. } & \text { Standard deviation } \\ \text { PRESS } & \text { Predicted residual error of sum of squares } \\ {[\mathrm{M}]} & \text { Molarity } \\ \text { ANOVA } & \text { Analysis of variance }\end{array}$

\section{References}

[1] Kumar A, Thakur A, and Panesar PS, Lactic acid and its separation and purification techniques, A review. Reviews in Environmental Science and Bio/Technology, (2019), 18, PP. 823-853. DOI: 10.1007/s11157-019-09517-w.

[2] Vijayakumar J, Aravindan R, and Viruthagiri T, Recent trends in the production, purification and application of lactic acid, Chemical and Biochemical Engineering, (2008), 22 (2), PP. 245265.

[3] Pal P, Sikder J, Roy S, Giorno L, Process intensification in lactic acid production: A review of membrane-based processes, Chemical Engineering and Processing, (2009), 48(11-12), PP. 1549-1559. DOI: 10.1016/j.cep.2009.09.003.

[4] Narayana N, Roy Choudhury PK, Srivastava A, L(+) - lactic acid fermentation and its product polymerization, Electronic Journal of Biotechnology, (2004), 7(2), PP. 167-179. DOI: 10.2225/vol7-issue2-fulltext-7.

[5] Kelkar ST and Mahanwar PA, Production of lactic acid from tamarind kernel by lactobacillus casei, International Journal of Technology, (2015), 3(5), PP. 25-31.

[6] Ghaffar T, Irshad M, Anwar Z, Aqil T, Zulifqar Z, Tariq A, Kamran M, Ehsan N, and Mehmood S, Recent trends in lactic acid biotechnology: A brief review on production to purification, Journal of Radiation Research and Applied Science, (2014), $7(2), \quad$ PP. 222-229. DOI: 10.1016/j.jrras.2014.03.002.

[7] Wasewar KL, Pangarkar VG, Heesink ABM, and Versteeg GF, Intensification of enzymatic conversion of glucose tolactic acid by reactive extraction, Chemical Engineering Science, (2003), 58 (15), PP. 3385-3393. DOI: 10.1016/S00092509(03)00221-5.

[8] Krzyzaniak A, Leeman M, Vossebeld F, Visser TJ, Schuur B,andHaan AB, Novel extractants for the recovery of fermentation derived lactic acid, Separation and Purification Technology, (2013), 111, PP. 82-89. DOI: 10.1016/j.seppur.2013.03.031.

[9] Keshav A, Wasewar LK, and Chand S, Reactive extraction of propionic acid using tri-n-octylamine, tri-n-butyl phosphate and aliquat336 in sunflower oil as diluent, Journal of chemistry Technology Biotechnology, (2009), 84(4), PP. 484-489. DOI: $10.1002 /$ jctb.2066.

[10] Yebo L, Abolghasem S, Karen W, and Caixia W, Separate and concentrate lactic acid using combination of nano-filtration and reverse osmosis membranes, Applied Biochemistry and Biotechnology, (2008), 147(1-3), PP. 1-9. DOI: 10.1007/s12010-007-8047-5.

[11] Wasewar KL, Reactive Extraction: An Intensifying approach for carboxylic acid separation, International Journal of Chemical Engineering and Applications, (2012), 3(4), PP. 249-255. Doi: 10.7763/IJCEA.2012.V3.195.

[12] Keshav A, Chand S, and Wasewar KL, Recovery of propionic acid from aqueous phase by reactive extraction using quarternary amine (Aliquat336) in various diluents, Chemical Engineering Journal, (2009), 152(1), PP. 95-102. DOI: 10.1016/j.cej.2009.03.037.

[13]Poposka FA, Prochazka J, Tomovska R, Nikolovskia K, and Grizo A, Extraction of tartaric acid from aqueous solutions with tri-iso-octylamine (HOSTAREX A-324) Equilibrium and kinetics, Chemical Engineering Science (2000), 55(9), PP. 1591-1604. Doi: 10.1016/S0009-2509(99)00416-9.

[14] Uslu H and Inci I, (Liquid-liquid) equilibria of the (water + propionic acid + Aliquat336 + organic solvents) at $\mathrm{T}=298.15 \mathrm{~K}$, Journal Chemical Thermodynamic, (2007), 39(5), PP. 804-809. DOI: 10.1016/j.jct.2006.10.001.

[15] Morales AF, Albet J, Kyuchoukov G, Malmary G, and Molinier J, Influence of extractant (TBP and TOA), diluent, and modifier on extraction equilibrium of monocarboxylic acids, Journal Chemical Engineering Data, (2003), 48(4), PP. 874-886. DOI: 10.1021/je020179o.

[16] Danner H, Madzingaidzo L, Holzer M, Mayrhuber $\mathrm{L}$, and Braun, R, Extraction and purification of lactic acid from silages, Bioresource Technology, 
(2000), 75 (3), PP. 181-187. DOI: 10.1016/S09608524(00)00068-7.

[17] Harington T and Hossain M, Extraction of lactic acid into sunflower oil and its recovery into an aqueous solution, Desalination, (2008), 218(1-3), PP. 287-296. DOI: 10.1016/j.desal.2007.02.024.

[18]Kumar A, Thakur A, Panesar PS, Recent developments on sustainable solvents for emulsion liquid membrane processes, Journal of Cleaner Production, (2019,) 240, 118250. DOI: 10.1016/j.jclepro.2019.118250.

[19] Playne MJ and Smith BR, Toxicity of organic extraction reagents to anaerobic bacteria. Biotechnology Bioengineering, (1983), 25(5), PP. 1251-1265. DOI:10.1002/bit.260250508.

[20] Yabannavar VM and Wang DIC, Strategies for reducing solvent toxicity in extractive fermentations, Biotechnology Bioengineering, (1991), 37(8), PP. $\quad$ 716-722. DOI: 10.1002/bit.260370805.

[21] Srivastava A and Prasad R, Triglycerides-based diesel fuel, Renewable Sustainable Energy Review, (2000), 4, PP. 111-133. DOI: 10.1016/S13640321(99)00013-1.

[22]Collins FI and Sedgwick VE, Fatty acid composition of several varieties of soybeans, Journal of the American Oil Chemists Society, (1959), 36(12), PP. 641-644. DOI: 10.1007/BF02640276.

[23] Kumar A, Thakur A, and Panesar PS, A comparative study on experimental and response surface optimization of lactic acid synergistic extraction using green emulsion liquid membrane, Separation and Purification Technology, (2019), 211, PP. 54-62. DOI: 10.1016/j.seppur.2018.09.048.

[24]Kumar A, Thakur A, and Panesar PS, Statistical optimization of lactic acid extraction using green emulsion ionic liquid membrane (GEILM), Journal of Environmental Chemical Engineering, (2018), 6, PP. 1855-1864. DOI: 10.1016/j.jece.2018.01.037.

[25] Kimberley AC and Taylor CA, Simple colorimetric assay for muramic acid and lactic acid, (1996), Applied Biochemistry Biotechnology, 56, 49-58.

[26]Kumar A and Thakur A, Parametric optimization of green synergistic reactive extraction (GSRE) of lactic acid using trioctylamine, aliquat336, and butan-2-ol in sunflower oil by response surface methodology (RSM), Chemical Engineering Communication, (2019), 206, PP. 1072-1086. DOI: 10.1080/00986445.2018.1544898.

[27] Athankar KK, Verma MN, Shende DZ, KYoo CK, and Wasewar KL, Reactive extraction of phenylacetic acid with tri-n-butyl phosphate in benzene, hexanol, and rice bran oil at $298 \mathrm{~K}$, Journal Chemical Engineering, (2013), 58(11), PP. 3240-3248. DOI: 10.1021/je400696d.

[28] Waghmare MD, Wasewar KL, Sonawane SS, and Shende DZ, Reactive extraction of picolinic and nicotinic acid by natural non-toxic solvent, Separation and Purification Technology, (2013), $120 \quad$ (20), PP. 296-303. DOI.org/10.1016/j.seppur.2013.10.019.

[29] Rastogi NK and Chanukya BS, Supported liquid membrane composed of tertiary and quaternary amine for the extraction of lactic acid, International journal of membrane science and technology, (2015), 2(2), PP.19-28. DOI: 10.15379/2410-1869.2015.02.02.03.

[30] Kumar S, Datta D, and Babu BV, Estimation of equilibrium parameters using differential evolution in reactive extraction of propionic acid by tri-nbutyl phosphate, Chemical Engineering and Processing, (2014), 50(7), PP. 614-622. DOI: 10.1016/j.cep.2011.03.004

[31] Udachan IS and Sahoo AK, A study of parameters affecting the solvent extraction of lactic acid from fermentation broth, Brazilian Journal of Chemical Engineering, (2004), 31 (3), PP. 1-7. DOI: 10.1590/0104-6632.201431s00002495.

[32] Prasad KN, Hassan FA, Yang B, Kong KW, Ramanan NR, Azlan A, and Ismail A, Response surface optimisation for the extraction of phenolic compounds and antioxidant capacities of underutilised mangiferapajangkosterm. peels, Food Chemistry, (2011), 128(4), PP. 1121-1127. DOI: 10.1016/j.foodchem.2011.03.105.

[33] Bas D and Ismail HB, Modeling and optimization usability of response surface methodology, Journal of Food Engineering, (2007), 78(3), PP. 836-845. DOI: 10.1016/j.jfoodeng.2005.11.024

[34] Pathirana CL and Shahidi F, Optimization of extraction of phenolic compounds from wheat using response surface methodology, Food Chemistry, (2005), 93(1), PP. 47-56. DOI: 10.1016/j.foodchem.2004.08.050.

[35] Swarnkar A, Keshav A, Das AK, and Soni AB, Modeling of the recovery of citric acid using aliquat336 in natural diluents, International Journal of Scientific Engineering and Research, (2014), 2(11), PP. 2347-3878.

[36] Chanukya BS, Kumar M, and Rastogi NK, Optimization of lactic acid pertraction using liquid emulsion membranes by response surface 
methodology, Separation and Purification Technology, (2013), 111, PP. 1-8, DOI: 10.1016/j.seppur.2013.03.026

[37] Datta D, Kumar S, and Uslu H, Status of the Reactive extraction as a method of separation, Journal of Chemistry, (2015), 2015, PP. 1-16. DOI: $10.1155 / 2015 / 853789$

[38] Avinash T, Panesar PS, and Saini MS, Parametric optimization of lactic acid extraction from aqueous solution in a mixed flow reactor using emulsion liquid membrane by response surface methodology, Chemical and Biochemical Engineering, (2008), 22(2), 157-167.

[39] Kahya E, Bayraktar E, and Mehmetoglu U, Optimization of process parameters for reactive lactic acid extraction, Turkish Journal of Chemistry, (2000), 25, PP. 223-230.

[40]Hong YK and Hong WH, Removal of acetic acid from aqueous solutions containing succinic acid and acetic acid by tri-n-octylamine, Separation and Purification Technology, (2005), 42(2), PP. 151157. DOI: 10.1016/j.seppur.2004.03.015.

[41] Keshav A, Wasewar KL, and Chand S, Extraction of propionic acid with tri-n-octylamine in different diluents, Separation and Purification Technology, (2008), 63(1), PP.179-183. DOI: 10.1021/ie800006r.

[42] Marchitan N, Cojocaru C, Mereuta A, Duca GH, Cretescu I, and Gonta M, Modeling and optimization of tartaric acid reactive extraction from aqueous, solutions: A comparison between response surface methodology and artificial neural network, Separation and Purification Technology, (2011), 75(3), PP. 273-285. DOI: 10.1016/j.seppur.2010.08.016.

[43] Kumar A and Thakur A, Reactive extraction of lactic acid using environmentally benign green solvents and synergistic mixture of extractants, Scientia Iranica (C), 2019, 26(6), PP. 3456-3467. DOI: $10.24200 /$ SCI.2019.52233.2610.

[44] Matsumoto M, Otono T, and Kondo K, Synergistic extraction of organic acids with tri-n-octylamine and tri-n-butyl-phosphate, Separation and Purification Technology, 2001, 24 (1-2), PP. $337-$ 342. DOI: 10.1016/S1383-5866(01)00137-X.

[45] Tian M, Jia Q, and Liao W, Studies on synergistic solvent extraction of rare earth elements fromnitrate medium by mixtures of 8 hydroxyquinoline with Cyanex301 or Cyanex302, Journal of Rare Earths, (2013), 31(6), PP. 604608. DOI: 10.1016/S1002-0721(12)60328-7.

[46] Jiang D, Song N, Liao S, Lian Y, Ma J, and Jia Q, Study on the synergistic extraction of vanadium by mixtures of acidic organophosphorus extractants and primary amine N1923, Separation and Purification Technology, (2015), 156(2), PP. 835840. DOI: $\quad 10.1016 /$ j.seppur.2015.11.008 